\title{
Multiresidue method for the simultaneous analysis of antibiotics and mycotoxins in feeds by ultra-high performance liquid chromatography coupled to tandem mass spectrometry
}

\author{
Ü.I. $\operatorname{Konak}^{1^{*} \oplus \text {, H.A. Yatmaz }}{ }^{2}$, Ş. Nilüfer ${ }^{2}$, T. Erkaymaz ${ }^{3}$ and M. Certel ${ }^{4}$
}

\footnotetext{
${ }^{1}$ Department of Food Engineering, Faculty of Engineering and Architecture, Avrasya University, 61250, Trabzon, Turkey

${ }^{2}$ Food Safety and Agricultural Research Center, Akdeniz University, 07059, Antalya, Turkey

${ }^{3}$ Rose and Rose Products Research and Application Center, Süleyman Demirel University, 32260, Isparta, Turkey

${ }^{4}$ Department of Food Engineering, Faculty of Engineering, Akdeniz University, 07059, Antalya, Turkey
}

\section{ORIGINAL RESEARCH PAPER}

Received: June 2, 2020 • Accepted: August 31, 2020

Published online: February 12, 2021

(C) 2020 The Author(s)

\section{ABSTRACT}

Residues in animal feeds and foods of animal origin have been important safety issue concerning both human and animal health. A multiresidue method for determination of eight mycotoxins and ten antibiotics was developed and validated in animal feeds by using QuEChERS (quick, easy, cheap, effective, rugged, and safe) extraction followed by UHPLC-MS/MS. Optimisation of UHPLC-MS/MS parameters was performed to achieve good separation and resolution. The method was validated according to the European Commission Decision 2002/657/EC. Matrix matched calibration curves showed good $r^{2}(\geq 0.995)$ values, and limit of quantification (LOQ) values varied between 1.2 and $5.2 \mu \mathrm{g} \mathrm{kg}^{-1}$. Average recoveries ranged from 60 to $102 \%$ with relative standard deviations of 2.2 and $15.6 \%$ for all type of feed samples except for tetracyclines, lincomycin, tylosin, ochratoxin $A$, and fumonisin $\left(B_{1}\right.$ and $\left.B_{2}\right)$.

\footnotetext{
*Corresponding author. Tel.: +90 462 3440511; fax: +90 462 3340550; E-mail: ulgen.ilknur.konak@avrasya.edu.tr
} 


\section{KEYWORDS}

multiresidue, feed, QuEChERS, UHPLC-MS/MS, validation

\section{INTRODUCTION}

Antibiotics are used regularly for the treatment of diseases in animals. Additionally, they are applied to animals for enhancing feed efficiency and growth rate (Greenless et al., 2012). Residues can occur in the edible tissues of the animals due to antibiotic usage in food producing animals. These residues can be toxic for humans and may develop allergic reactions or produce antibiotic-resistance pathogens in humans. Furthermore, they can even cause death (Gentili et al., 2005; Wang et al., 2006). Mycotoxins are small and toxic chemical products formed by different fungal species. These species can contaminate feedstuff with toxins during cultivation or after harvest and cause a toxic response when ingested by vertebrate species (Turner et al., 2009; Wang et al., 2015). Humans can be exposed to mycotoxins through the consumption of contaminated agricultural products or their metabolites in animal-derived products such as milk and egg. Additionally, exposure can also occur via dermal contact (Capriotti et al., 2012).

QuEChERS method consists of two steps: extraction with acetonitrile followed by liquidliquid partitioning and purification with dispersive solid-phase extraction (d-SPE). The method was introduced as multiresidue analysis for pesticide residues in high moisture fruits and vegetables in 2002 (Rejczak and Tuzimski, 2015). However, applications of this method have been reported to additionally detect residues of antibiotics (Lopes et al., 2012; Robert et al., 2015) and mycotoxins (Dzuman et al., 2014; Qian et al., 2018) in feeds. UHPLC-MS/MS device has been extensively used for detection, identification, and quantification of multiclass antibiotic residues (Boscher et al., 2010; Zhang et al., 2013; Qian et al., 2019) or multiclass mycotoxin residues (Streit et al., 2013; Dzuman et al., 2014; Wang et al., 2015), individually. The objective of the present work was to develop a multi-residue UHPLC-MS/MS method using QuEChERS extraction to simultaneously detect and quantify antibiotics and mycotoxins in different types of animal feeds. The antibiotic and mycotoxin standards were selected according to their use in all food producing animal species (Ronquillo and Hernandez, 2017) and the degree of contamination in feed (Streit et al., 2013), respectively.

\section{MATERIALS AND METHODS}

\subsection{Samples and chemicals}

Twenty-seven different feed samples for poultry, cattle, and fish were collected from local feed markets in Antalya, Turkey and stored at $4{ }^{\circ} \mathrm{C}$ prior to analysis. All standards and chemicals were of high purity grade and supplied by Sigma-Aldrich (Steinheim, Germany). QuEChERS extraction-dispersive kits (Bond Elut) were supplied by Agilent (CA, USA). Individual stock solutions were prepared at $1,000 \mathrm{mg} \mathrm{L}^{-1}$ in methanol. A working mix from the standard solution of $5 \mathrm{mg} \mathrm{L}^{-1}$ was prepared by transferring an appropriate aliquot of each stock solution into methanol. All stocks and working solutions were stored at $-18^{\circ} \mathrm{C}$ in the dark. 


\subsection{QuEChERS extraction}

The QuEChERS extraction method was performed according to AOAC Official Method (AOAC, 2007).

\subsection{UHPLC-MS/MS}

UHPLC-MS/MS analyses were performed with a triple quadrupole TSQ Quantum Access Max (Thermo Fisher Scientific, CA, USA) equipped with Accela UHPLC system (Thermo Fisher Scientific, CA, USA). Chromatographic separations were performed with a Hypersil Gold ${ }^{\mathrm{TM}}$ aQ column $(100 \times 2.1 \mathrm{~mm}, 1.9 \mu \mathrm{m}$, Thermo Fisher Scientific, CA, USA $)$. The mobile phase A consisted of water with $0.5 \mathrm{mM}$ oxalic acid and $1 \mathrm{mM}$ ammonium formate, and the mobile phase B consisted of methanol with $0.2 \mathrm{mM}$ oxalic acid. The gradient elution was: $90 \% \mathrm{~A}$ and $10 \% \mathrm{~B}$ for $2.5 \mathrm{~min}$, then linearly changed to $0 \% \mathrm{~A}$ and $100 \% \mathrm{~B}$ in $1.5 \mathrm{~min}$, and held constant for $2 \mathrm{~min}$; then linearly changed $90 \%$ and $10 \%$ in $1 \mathrm{~min}$, and finally held constant for $2 \mathrm{~min}$. The total run time was $9 \mathrm{~min}$. The flow rate of the mobile phase was $400 \mu \mathrm{L} \mathrm{min}{ }^{-1}$, the column temperature was set at $40{ }^{\circ} \mathrm{C}$, and the injection volume was $10 \mu \mathrm{L}$. Electrospray ionisation was performed in the positive ion mode $(\mathrm{ESI}+)$, and the mass spectrometer was operated in a multiple-reaction monitoring (MRM) mode. The ion spray voltage was set at $3.2 \mathrm{kV}$, capillary voltage at $35 \mathrm{~V}$, and the tube lens voltage at $82 \mathrm{~V}$. The capillary temperature and vaporiser temperature were set at $250{ }^{\circ} \mathrm{C}$ and $350{ }^{\circ} \mathrm{C}$, respectively. Sheath and auxiliary gas flow rates were 40 and 10 units, respectively. Data acquisition was done with Xcalibur 2.1 software with Qual and Quanbrowser.

\subsection{Method validation}

The following parameters were evaluated during method validation within laboratory: selectivity, linearity, limit of detection (LOD), limit of quantification (LOQ), accuracy and precision (repeatability and reproducibility) (Commission Decision, 2002).

\subsection{Statistical analysis}

Significant differences among UHPLC parameters were evaluated with analysis of variance (ANOVA) by using SAS System Software (SAS Institue Inc., Cary, NC, USA). Duncan's Multiple Range test $(P<0.05)$ was used to compare significant differences observed in mean values of the results.

\section{RESULTS AND DISCUSSION}

\subsection{UHPLC-MS/MS parameters}

Hypersil Gold ${ }^{\mathrm{TM}}$ aQ column was selected to ensure good peak shape and resolution when using gradient elution with aqueous mobile phase (Konak et al., 2017). Therefore, UHPLC application was performed with reversed-phase chromatography by using Hypersil Gold ${ }^{\mathrm{TM}}$ aQ column in this study. In order to optimise the chromatographic conditions for antibiotics and mycotoxins, effects of different mobile phases (methanol and acetonitrile) and mobile phase additives (formic acid, acetic acid, and oxalic acid) on signal intensity were studied first. 
In general, better separation in UHPLC was obtained with methanol than acetonitrile. In addition, the intensity of the target analytes was also higher in MS with methanol $(P<0.05)$. Different concentrations of formic acid (0.05 and $0.1 \%)$, acetic acid ( 0.1 and $0.2 \%)$, and oxalic acid $(0.25$ and $0.5 \mathrm{mM})$ were used to enhance ionisation of the analytes. The results showed that signal intensities of the analytes were higher at the concentrations of $0.05 \%$ for formic acid, $0.1 \%$ for acetic acid, and $0.5 \mathrm{mM}$ for oxalic acid $(P<0.05)$. Furthermore, the highest signal intensity of the analytes was obtained by using oxalic acid instead of formic or acetic acid $(P<0.05)$. Moreover, optimum peak shapes and reproducible analyte signals were achieved by using oxalic acid with ammonium formate $(1 \mathrm{mM})$ in methanol. The use of an acidic mobile phase with salt promoted positive ionisation and provided the stability of the analysis.

Different gradient elution programs were tested to provide the desired separation of the target analytes. Additionally, other parameters such as flow rate $\left(400,500\right.$, and $\left.600 \mu \mathrm{L} \mathrm{min}{ }^{-1}\right)$, column temperature $\left(20,30\right.$, and $\left.40{ }^{\circ} \mathrm{C}\right)$, and injection volume (10 and $\left.20 \mu \mathrm{L}\right)$ were also tested to get a fast separation and good peak shape. The best result was obtained when the flow rate was $400 \mu \mathrm{L} \mathrm{min}{ }^{-1}$, column temperature was $40{ }^{\circ} \mathrm{C}$, and injection volume was $10 \mu \mathrm{L}(P<0.05)$.

Mass spectrometry parameters were optimised to achieve the highest signal intensity for the target analytes (Fig. 1). Each standard solution was infused directly into the mass analyser in order to determine the precursor ion and two product ions of the target analytes in scan mode.

A

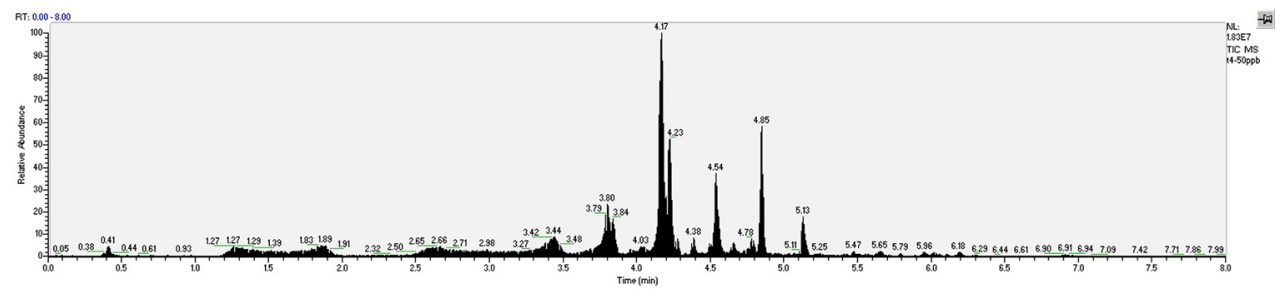

B

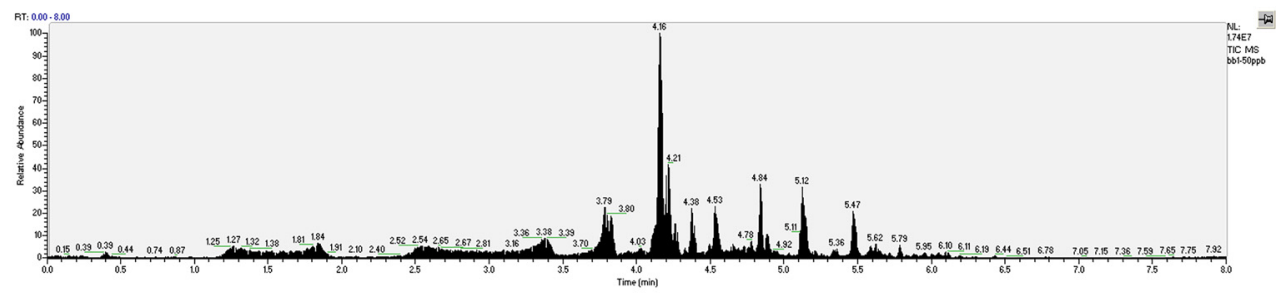

$\mathrm{C}$

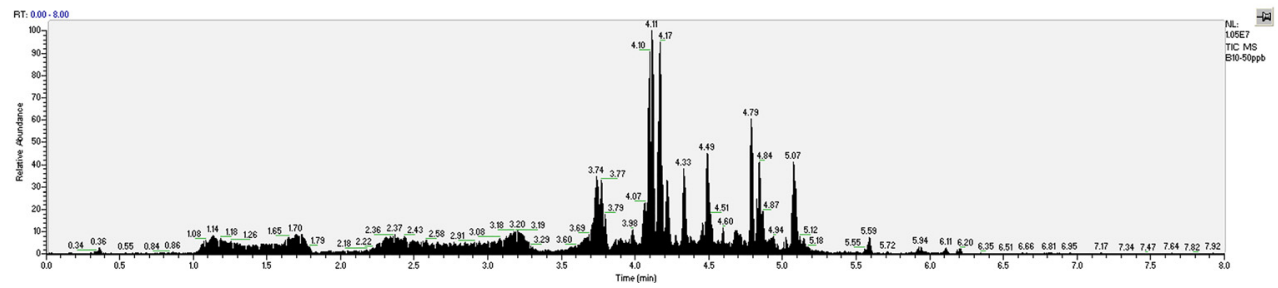

Fig. 1. UHPLC-MS/MS chromatograms for poultry (A), cattle (B), and fish (C) feed spiked with $50 \mu \mathrm{g} \mathrm{kg}^{-1}$ 
Table 1. Retention time (RT) and multiple reaction monitoring conditions for each compound

\begin{tabular}{lccccc}
\hline Compound & RT $(\mathrm{min})$ & $\begin{array}{c}\text { Precursor } \\
\text { ion }(\mathrm{m} / \mathrm{z})\end{array}$ & $\begin{array}{c}\text { Quantifier } \\
\text { ion }(\mathrm{m} / \mathrm{z})\end{array}$ & $\begin{array}{c}\text { Qualifier } \\
\text { ion }(\mathrm{m} / \mathrm{z})\end{array}$ & $\begin{array}{c}\mathrm{CE} \\
(\mathrm{eV})\end{array}$ \\
\hline Sulfamerazine & $1.15-2.05$ & 265 & 156 & 172 & 20 \\
Lincomycin & $2.30-3.30$ & 407 & 126.2 & 359 & 25 \\
Sulfamethazine & $2.40-3.63$ & 279 & 186 & 156 & 20 \\
Tetracycline & 3.80 & 445 & 410 & 427 & 15 \\
Oxytetracycline & 3.84 & 461 & 426 & 443 & 15 \\
Sulfadimethoxine & 4.17 & 311 & 156 & 245 & 20 \\
Chlortetracycline & 4.18 & 479 & 444 & 462 & 20 \\
Sulfaquinoxaline & 4.23 & 301 & 156 & 108.2 & 18 \\
Aflatoxin G1 & 4.28 & 329 & 243 & 215 & 35 \\
Aflatoxin B2 & 4.34 & 315 & 259 & 287 & 35 \\
Aflatoxin B1 & 4.38 & 313 & 241 & 269 & 35 \\
Tylosin & 4.50 & 917 & 174 & 773.1 & 35 \\
Erythromycin & 4.54 & 734 & 576 & 558 & 20 \\
Aflatoxin G2 & 4.54 & 331 & 313 & 285 & 35 \\
Fumonisin B1 & 4.61 & 723 & 353 & 705.1 & 35 \\
Ochratoxin A & 4.76 & 426 & 261 & 279 & 25 \\
Fumonisin B2 & 4.78 & 706 & 336 & 354 & 35 \\
Sterigmatocystin & 4.85 & 325 & 310 & 281 & 25 \\
\hline
\end{tabular}

The collision energy was optimised individually for each analyte. Retention time (RT) and MS/ MS transitions for quantification and confirmation of the analytes are shown in Table 1.

\subsection{Method validation}

Performance characteristics of the method were established by spiked blank feed samples selected from 27 samples. The linearity was evaluated by using six calibration points $(0,10,25$, 50,75 , and $100 \mu \mathrm{g} \mathrm{kg}^{-1}$ ) in the range of $0-100 \mu \mathrm{g} \mathrm{kg}^{-1}$. Peak area was selected as response and a coefficient of determination $\left(r^{2}\right)$ higher than 0.995 was obtained for all analytes. The low LOD and LOQ values of the developed method had the advantages of high selectivity, accuracy, and precision in simultaneous determination of the analytes.

Recovery experiments for the entire QuEChERS extraction and UHPLC-MS/MS procedure were carried out using blank matrix fortified at 10 and $100 \mu \mathrm{g} \mathrm{kg}^{-1}$ with six replicates for each fortification level. The obtained results showed that the extraction procedure was suitable for most of the analytes except for tetracycline, oxytetracycline, chlortetracycline, ochratoxin A, and fumonisin $\left(B_{1}\right.$ and $\left.B_{2}\right)$. Likewise, lower recovery values were observed for tetracycline groups during acetonitrile extraction performed on animal feed. Researchers noticed that the high volume of acetonitrile employed caused co-precipitation of the analytes with the proteins (Aguilera-Luiz et al., 2013). On the other hand, another study showed that clean-up step after extraction led to lower recoveries for tetracyclines (Bourdat-Deschamps et al., 2014). However, a clean-up step was essential to obtain accurate results, because interfering compounds could be co-extracted with the target compounds during extraction and caused a reduction in the lifetime of the chromatographic column. Recovery, repeatability (intraday precision), and reproducibility 
(interday precision) values belonging to the analytes used in the validation procedure within the laboratory were calculated for each matrix and summarised in Tables 2-4. According to the results, the average recovery values (between 60 and 102\%) were acceptable for most target compounds at two concentration levels, except for aflatoxin G2 with recovery of $58.3-59.2 \%$ in poultry feed. Additionally, RSD values were within the acceptable limit of $20 \%$. However, low recovery values of lincomycin and tylosin were obtained, especially at the lowest concentration level. It could be due to high polarity of the analytes, which resulted in low extraction with

Table 2. Validation parameters of the method in poultry feed

\begin{tabular}{lccccccc}
\hline & \multicolumn{3}{c}{$10 \mu \mathrm{g} \mathrm{kg}^{-1}$} & & \multicolumn{3}{c}{$100 \mu \mathrm{g} \mathrm{kg}^{-1}$} \\
\cline { 2 - 4 } Compound & $\begin{array}{c}\text { Recovery } \\
(\%)\end{array}$ & $\begin{array}{c}\text { Intraday } \\
\text { precision (\%) }\end{array}$ & $\begin{array}{c}\text { Interday } \\
\text { precision }(\%)\end{array}$ & $\begin{array}{c}\text { Recovery } \\
(\%)\end{array}$ & $\begin{array}{c}\text { Intraday } \\
\text { precision }\end{array}$ & $\begin{array}{c}\text { Interday } \\
\text { precision (\%) }\end{array}$ \\
\hline Tylosin & 12.96 & 13.81 & 13.72 & & 27.90 & 19.61 & 21.03 \\
Lincomycin & 20.01 & 4.33 & 1.28 & & 23.96 & 10.38 & 11.72 \\
Aflatoxin G2 & 59.15 & 5.92 & 5.38 & & 58.29 & 14.97 & 17.60 \\
Aflatoxin B1 & 71.11 & 7.35 & 4.21 & & 75.43 & 10.60 & 5.18 \\
Aflatoxin G1 & 73.51 & 6.55 & 2.70 & & 64.01 & 14.09 & 14.03 \\
Sulfadimethoxine & 73.80 & 3.35 & 2.10 & & 76.45 & 4.94 & 2.58 \\
Sulfamethazine & 75.86 & 5.54 & 3.68 & & 89.89 & 5.40 & 5.14 \\
Aflatoxin B2 & 76.49 & 5.21 & 1.52 & & 80.33 & 14.56 & 6.22 \\
Sulfaquinoxaline & 77.13 & 7.75 & 6.0 & & 72.73 & 4.45 & 3.43 \\
Erythromycin & 84.04 & 5.76 & 6.62 & & 69.40 & 11.03 & 8.07 \\
Sulfamerazine & 90.67 & 4.35 & 3.47 & & 78.54 & 6.69 & 4.15 \\
Sterigmatocystin & 95.05 & 3.99 & 4.42 & & 82.95 & 4.99 & 4.36 \\
\hline
\end{tabular}

Table 3. Validation parameters of the method in cattle feed

\begin{tabular}{lccccccc}
\hline & \multicolumn{3}{c}{$10 \mu \mathrm{g} \mathrm{kg}^{-1}$} & & \multicolumn{3}{c}{$100 \mu \mathrm{gg}^{-1}$} \\
\cline { 2 - 4 } Compound & $\begin{array}{c}\text { Recovery } \\
(\%)\end{array}$ & $\begin{array}{c}\text { Intraday } \\
\text { precision } \\
(\%)\end{array}$ & $\begin{array}{c}\text { Interday } \\
\text { precision } \\
(\%)\end{array}$ & & $\begin{array}{c}\text { Recovery } \\
(\%)\end{array}$ & $\begin{array}{c}\text { Intraday } \\
\text { precision } \\
(\%)\end{array}$ & $\begin{array}{c}\text { Interday } \\
\text { precision } \\
(\%)\end{array}$ \\
\hline Tylosin & 13.82 & 16.60 & 9.23 & & 20.70 & 15.88 & 17.97 \\
Lincomycin & 14.96 & 10.55 & 13.22 & & 16.30 & 7.46 & 6.89 \\
Aflatoxin G2 & 69.87 & 3.93 & 4.26 & & 91.59 & 11.14 & 3.14 \\
Aflatoxin B1 & 71.02 & 5.28 & 4.42 & & 72.45 & 7.27 & 10.38 \\
Aflatoxin G1 & 75.31 & 9.74 & 4.57 & & 73.50 & 8.85 & 6.33 \\
Sulfadimethoxine & 75.60 & 3.43 & 2.35 & & 68.16 & 8.53 & 6.86 \\
Sulfamethazine & 76.44 & 8.38 & 9.74 & & 69.43 & 2.24 & 1.61 \\
Aflatoxin B2 & 77.88 & 7.26 & 8.21 & & 65.14 & 5.64 & 5.82 \\
Sulfaquinoxaline & 78.39 & 9.08 & 5.60 & & 76.50 & 4.76 & 2.95 \\
Erythromycin & 78.41 & 4.08 & 1.90 & & 79.07 & 7.18 & 6.50 \\
Sulfamerazine & 84.34 & 4.01 & 2.77 & & 85.38 & 4.53 & 2.76 \\
Sterigmatocystin & 89.27 & 5.29 & 6.07 & & 72.29 & 3.26 & 1.62 \\
\hline
\end{tabular}


Table 4. Validation parameters of the method in fish feed

\begin{tabular}{lccccccc}
\hline & \multicolumn{3}{c}{$10 \mu \mathrm{kg}^{-1}$} & & \multicolumn{3}{c}{$100 \mu \mathrm{g} \mathrm{kg}^{-1}$} \\
\cline { 2 - 4 } Compound & $\begin{array}{c}\text { Recovery } \\
(\%)\end{array}$ & $\begin{array}{c}\text { Intraday } \\
\text { precision } \\
(\%)\end{array}$ & $\begin{array}{c}\text { Interday } \\
\text { precision } \\
(\%)\end{array}$ & & $\begin{array}{c}\text { Recovery } \\
(\%)\end{array}$ & $\begin{array}{c}\text { Intraday } \\
\text { precision } \\
(\%)\end{array}$ & $\begin{array}{c}\text { Interday } \\
\text { precision } \\
(\%)\end{array}$ \\
\hline Lincomycin & 25.57 & 11.23 & 10.08 & & 45.01 & 7.25 & 2.99 \\
Tylosin & 29.27 & 6.59 & 6.09 & & 43.06 & 16.73 & 18.41 \\
Aflatoxin G1 & 62.12 & 11.81 & 11.86 & & 68.04 & 10.83 & 7.40 \\
Aflatoxin B2 & 66.81 & 9.46 & 11.25 & & 69.69 & 10.93 & 8.46 \\
Sulfadimethoxine & 67.81 & 6.80 & 4.99 & & 65.79 & 4.23 & 2.84 \\
Aflatoxin B1 & 70.03 & 15.60 & 10.68 & & 61.37 & 6.52 & 3.09 \\
Sulfamethazine & 72.84 & 5.50 & 5.12 & & 86.01 & 8.50 & 11.04 \\
Sulfaquinoxaline & 74.18 & 3.92 & 3.13 & & 66.10 & 4.33 & 3.63 \\
Sulfamerazine & 78.90 & 4.71 & 3.70 & & 92.55 & 7.00 & 8.74 \\
Aflatoxin G2 & 79.47 & 6.69 & 5.39 & & 66.55 & 9.29 & 6.44 \\
Erythromycin & 80.35 & 10.26 & 10.26 & & 101.50 & 10.41 & 13.11 \\
Sterigmatocystin & 84.74 & 4.51 & 2.87 & & 68.76 & 5.41 & 2.36 \\
\hline
\end{tabular}

acetonitrile. In addition, differences between the recovery values of some analytes in different matrices could be due to the matrix effect resulting from the matrix complexity.

\section{CONCLUSIONS}

A multiresidue method was developed for rapid and simultaneous determination of antibiotics and mycotoxins in animal feeds. Chromatographic separation and detection of the target analytes were achieved in a single run via UHPLC-MS/MS conditions. The developed method was applied to the analysis of 27 animal feed samples ( 9 for poultry, 8 for cattle, and 10 for fish) collected from local feed markets in Antalya, Turkey, and no positive results were observed in feed samples. Standard QuEChERS extraction method can be improved by applying different extraction solvents or acidifying agents to increase the extraction yield and also the number of extracted analytes. Recovery values can be increased with changing the polarity of the extraction solvents.

\section{ACKNOWLEDGEMENT}

We thank the Scientific Research Projects Coordination Unit of Akdeniz University (Antalya, Turkey) for financial support (Grant number: FBA-2017-2718).

\section{REFERENCES}

Aguilera-Luiz, M.M., Romero-González, R., Plaza-Bolaños, P., Vidal, J.L.M., and Frenich, A.G. (2013). Wide-scope analysis of veterinary drug and pesticide residues in animal feed by liquid chromatography 
coupled to quadrupole-time-of-flight mass spectrometry. Analytical and Bioanalytical Chemistry, 405: 6543-6553.

AOAC. (2007). Official Methods of Analysis, 18th ed. Association of Official Analytical Chemists, Gaithersburg. Official Method 2007.01 Pesticide residues in foods by acetonitrile extraction and partitioning with magnesium sulfate.

Boscher, A., Guignard, C., Pellet, T., Hoffmann, L., and Bohn, T. (2010). Development of a multi-class method for the quantification of veterinary drug residues in feedingstuffs by liquid chromatographytandem mass spectrometry. Journal of Chromatography A, 1217: 6394-6404.

Bourdat-Deschamps, M., Leang, S., Bernet, N., Daudin, J.J., and Nélieu, S. (2014). Multi-residue analysis of pharmaceuticals in aqueous environmental samples by online solid-phase extraction-ultra-high-performance liquid chromatography-tandem mass spectrometry: optimisation and matrix effects reduction by quick, easy, cheap, effective, rugged and safe extraction. Journal of Chromatography A, 1349: 11-23.

Capriotti, A.L., Caruso, G., Cavaliere, C., Foglia, P., Samperi, R., and Lagana, A. (2012). Multiclass mycotoxin analysis in food, environmental and biological matrices with chromatography/mass spectrometry. Mass Spectrometry Reviews, 31: 466-503.

Commission Decision. (2002). 2002/657/EC of 12 August 2002 implementing Council Directive 96/23/EC concerning the performance of analytical methods and the interpretation of results. OJ L 221/8-37.

Dzuman, Z., Zachariasova, M., Lacina, O., Veprikova, Z., Slavikova, P., and Hajslova, J. (2014). A rugged high-throughput analytical approach for the determination and quantification of multiple mycotoxins in complex feed matrices. Talanta, 121: 263-272.

Gentili, A., Perret, D., and Marchese, S. (2005). Liquid chromatography-tandem mass spectrometry for performing confirmatory analysis of veterinary drugs in animal-food products. $\operatorname{Tr} A C$, 24: 704-733.

Greenless, K.J., Friedlander, L.G., and Boxall, A. (2012). Antibiotic residues in food and drinking water, and food safety regulations. In: Wang, J., MacNeil, J.D., and Kay, J.F. (Eds.), Chemical analysis of antibiotic residues in food, Wiley, New Jersey, pp. 111-123.

Konak, Ü.I., Certel, M., Şik, B., and Tongur, T. (2017). Development of an analysis method for determination of sulfonamides and their five acetylated metabolites in baby foods by ultra-high performance liquid chromatography coupled to high-resolution mass spectrometry (Orbitrap-MS). Journal of Chromatography B, 1057: 81-91.

Lopes, R.P., Passos, È.E.F., Filho, J.F.A., Vargas, E.A., Augusti, D.V., and Augusti, R. (2012). Development and validation of a method for the determination of sulfonamides in animal feed by modified QuEChERS and LC-MS/MS analysis. Food Control, 28: 192-198.

Rejczak, T. and Tuzimski, T. (2015). A review of recent developments and trends in the QuEChERS sample preparation approach. Open Chemistry, 13: 980-1010.

Robert, C., Gillard, N., Brasseur, P.Y., Ralet, N., Dubois, M., and Delahaut, P. (2015). Rapid multiresidue and multi-class screening for antibiotics and benzimidazoles in feed by ultra-high performance liquid chromatography coupled to tandem mass spectrometry. Food Control, 50: 509-515.

Ronquillo, M.G. and Hernandez, J. C. A. (2017). Antibiotic and synthetic growth promoters in animal diets: review of impact and analytical methods. Food Control, 72: 255-267.

Qian, M., Yang, H., Li, Z., Liu, Y., Wang, J., Wu, H., Ji, X., and Xu, J. (2018). Detection of 13 mycotoxins in feed using modified QuEChERS with dispersive magnetic materials and UHPLC-MS/MS. Journal of Separation Science, 41: 756-764.

Qian, M., Zhang, X., Zhao, H., Ji, X., Li, X., Wang, J., Wu, H., Xu, J., and Li, Z. (2019). A high-throughput screening method for determination of multi-antibiotics in animal feed. Journal of Separation Science, 42: $2968-2976$. 
Streit, E., Schwab, C., Sulyok, M., Naehrer, K., Krska, R., and Schatzmayr, G. (2013). Multi-mycotoxin screening reveals the occurrence of 139 different secondary metabolites in feed and feed ingredients. Toxins, 5: 504-523.

Turner, N.W., Subrahmanyam, S., and Piletsky, S.A. (2009). Analytical methods for determination of mycotoxins: a review. Analytica Chimica Acta, 632: 168-180.

Wang, R.G., Su, X.O., Cheng, F.F., Wang, P.L., Fan, X., and Zhang, W. (2015). Determination of 26 mycotoxins in feedstuffs by multifunctional clean-up column and liquid chromatography-tandem mass spectrometry. Chinese Journal of Analytical Chemistry, 43: 264-270.

Wang, S., Zhang, H.Y., Wang, L., Duan, Z.J., and Kennedy, I. (2006). Analysis of sulphonamide residues in edible animal products: a review. Food Additives and Contaminants, 23: 362-384.

Zhang, G.J., Fang, B.H., Liu, Y.H., Wang, X.F., Xu, L.X., Zhang, Y.P., and He, L.M. (2013). Development of a multi-residue method for fast screening and confirmation of 20 prohibited veterinary drugs in feedstuffs by liquid chromatography tandem mass spectrometry. Journal of Chromatography B, 936: $10-17$.

Open Access. This is an open-access article distributed under the terms of the Creative Commons Attribution-NonCommercial 4.0 International License (https://creativecommons.org/licenses/by-nc/4.0/), which permits unrestricted use, distribution, and reproduction in any medium for non-commercial purposes, provided the original author and source are credited, a link to the CC License is provided, and changes - if any - are indicated. 